\title{
DIFUSÃO ARQUIVÍSTICA E SUAS EXPRESSÕES NOS CURSOS DE GRADUAÇÃO EM ARQUIVOLOGIA NO BRASIL
}

\section{ARCHIVAL DIFFUSION AND ITS EXPRESSIONS IN THE ARCHIVAL SCIENCE UNDERGRADUATE COURSES IN BRAZIL}

\author{
Fernanda Frasson Martendala \\ Eva Cristina Leite da Silvab
}

\begin{abstract}
RESUMO
Introdução: A difusão é a função da Arquivologia que se relaciona à divulgação dos acervos e serviços de informação intermediada por arquivistas e é identificada por seu caráter inclusivo, ao reunir os usuários da informação (potenciais e frequentes, adequando os serviços prestados) a capitais informacionais. Objetivo: Reconhecendo o papel fundamental da temática "difusão" no ensino de graduação em Arquivologia no Brasil, o presente artigo se ocupará de caracterizar a abordagem da difusão arquivística nos currículos dos cursos de graduação em Arquivologia no Brasil. Metodologia: Como aspectos metodológicos, a presente pesquisa considerou a lógica de pesquisa qualitativa, utilizando a análise de conteúdo como instrumento. Resultados: Como resultados, quanto aos currículos analisados, observa-se que as disciplinas que trabalham a temática da difusão, em sua maioria obrigatórias, abordam-na com diferentes enfoques e utilizam, para seu ensino, diferentes bibliografias. Conclusões: Conclui-se que nos currículos de Arquivologia a difusão é abordada, majoritariamente, nas disciplinas voltadas à descrição arquivística, seguida por disciplinas voltadas diretamente à difusão da informação e, com menor proporção, às disciplinas correlacionadas à mediação, competência e comunicação da informação.
\end{abstract}

Descritor: Disseminação da informação. Informação orgânica. Currículos. Programas de curso.

\footnotetext{
a Doutoranda em Ciências Sociais na Universidad de Buenos Aires/Argentina. Docente do Departamento de Ciencias de la Información da Universidad Nacional del Nordeste/Argentina. E-mail: fernanda.martendal@hotmail.com.

b Doutora em Educação pela Universidade Estadual de Campinas (UNICAMP). Docente do Programa de Pós-Graduação em Ciência da Informação da Universidade Federal de Santa Catarina (PGCIN-UFSC). E-mail: eva.cristina@ufsc.br.
} 


\section{INTRODUÇÃO}

Este artigo resulta de pesquisa realizada no contexto do Mestrado em Ciência da Informação, cursado na Universidade Federal de Santa Catarina, com dissertação defendida no ano de 2018. Como objetivo geral, a dissertação pretendeu analisar as abordagens da difusão na Arquivologia na literatura científica e suas expressões nos currículos dos cursos de graduação em Arquivologia no Brasil e, para tanto, propusemos três objetivos específicos: a) Identificar a abordagem da difusão na Arquivologia no escopo da literatura em Arquivologia, Ciência da Informação e Educação; b) Caracterizar a abordagem da difusão na Arquivologia nos currículos dos cursos de graduação em Arquivologia no Brasil; c) Apontar possíveis categorias de uso para o termo "difusão" no âmbito pesquisado.

No entanto, para este artigo optou-se por contemplar e apresentar as etapas do estudo que convergem somente com o objetivo específico "caracterizar a abordagem da difusão arquivística nos currículos dos cursos de graduação em Arquivologia no Brasil", para que se possa apreender com profundidade na temática analisada.

Considera-se que a difusão para a Arquivologia é uma das sete funções que está vinculada diretamente à função social que contém o arquivo (ALBERCH I FUGUERAS, 2003), à sociedade da informação (CASTELLS, 2016) e ao paradigma social da Ciência da Informação (CAPURRO, 2003), porque congrega aspectos que trabalham dinamicamente entre a informação orgânica, o usuário da informação e o arquivo. Este trabalho também faz menção à capacidade do arquivo de ser um espaço de intercâmbio e de processos de formação, para onde os usuários podem ir para pesquisar e de onde poderão sair os documentos para serem pesquisados, por meio de ações educativas.

Desta forma, ao perceber a centralidade da temática para a Arquivologia e frente às prerrogativas legais, principalmente da Lei de Acesso à Informação, surge 0 interesse de pesquisar de que maneira a difusão é abordada nos currículos dos cursos de graduação em Arquivologia nas universidades públicas do Brasil. Considerando que é uma temática emergente e em constante 
atualização, principalmente pelo avanço das tecnologias de informação e comunicação e as necessidades de usuários millenials e centennials que, cada vez mais demandam serviços diferenciados, um dos pressupostos da pesquisa é o de que: os cursos de Arquivologia devem acompanhar as novas nuances da área, oferecendo formação para poder dotar os futuros arquivistas de habilidades necessárias para o exercício da profissão.

Por isso, a presente pesquisa se estrutura pela definição de informação orgânica, de difusão arquivística e de sua caracterização como um processo, que implica a participação ativa do arquivista e do usuário da informação. Aborda os processos comunicativos na Arquivologia e as habilidades que devem ser desenvolvidas pelo arquivista, para poder cumprir e superar as expectativas do público. Em seguida, define a difusão arquivística como ação também educativa, que pode ser impulsionada desde em ambientes formais de educação (escolas, universidades), por meio de atividades desenvolvidas nestes espaços com documentos de arquivo, e em ambientes não formais (arquivos), onde o público realiza visitas e atividades dentro da instituição.

Os aspectos metodológicos buscaram encontrar marcas da difusão dentro dos currículos de 16 cursos de Arquivologia brasileiros e os resultados os acompanharam, apresentando a realidade encontrada: algumas das universidades pesquisadas acompanham a evolução das pesquisas em difusão, incluindo conteúdos que versam sobre uma difusão, usuários e profissionais considerados ativos (LOUSADA, 2015), e outras utilizam a difusão ainda como conceito atrelado estritamente ao marketing advindo da Administração, sem fazer a ponte necessária com a Arquivologia, por meio da inclusão de bibliografia relacionada à área em seus programas, por exemplo.

\section{A DIFUSÃO DA INFORMAÇÃO ORGÂNICA}

No âmbito da Arquivologia, o termo difusão remonta ao início do século XIX, momento em que "[...] os arquivistas começaram a sentir que a difusão dos arquivos Ihes dizia respeito, difusão essa que assumiu diversas formas como a cópia, a reprodução e a exposição temática de documentos" (ROUSSEAU; COUTURE, 1998, p.51). Por relacionar-se diretamente com o acesso e uso da 
informação pelos usuários, ela é reconhecida como uma das sete funções arquivísticas e reúne características relacionadas ao acesso à informação orgânica, aos serviços de referência em arquivos, à mediação desses serviços, ao caráter ativo dos usuários da informação, às necessidades destes usuários, ao caráter pedagógico do acervo, contemplando o rol cultural, administrativo e científico do arquivo.

Mais do que um meio para dar acesso à informação, a difusão está relacionada com a ética profissional do arquivista que, no trabalho que realiza, se compromete com a memória e a cidadania, desenvolve funções educativas no arquivo e considera as necessidades e comportamentos dos usuários. A difusão demanda alinhamento com as outras seis funções arquivísticas; elas se complementam, no entanto, a difusão reúne características que a identificam como próprias do contato direto entre arquivista, arquivo e usuário e expressa o objetivo maior de todas as demais funções arquivísticas, o acesso à informação.

Charbonneau (2008) e Rockembach (2015) confrontam duas visões sobre a difusão, em que abordam suas áreas de atuação, que englobam a informação, o profissional e o usuário:

[...] a difusão é a ação de fazer conhecer, de por em valor, de transmitir ou de deixar acessíveis uma ou várias informações contidas em documentos de arquivos a seus usuários (pessoas ou organismos) conhecidos ou potenciais para responder a suas necessidades específicas. A difusão dos arquivos é ainda uma atividade de múltiplos aspectos, pois compreende todas as relações mantidas pelo pessoal do centro de arquivos com sua clientela interna ou externa, e isso, nas três idades dos documentos (CHARBONNEAU, 2008, p. 374, tradução nossa, grifo nosso).

Charbonneau (2008) defende que a difusão se coloca num espaço atemporal dentro do arquivo. Não pertence somente à idade permanente, disponibilizando informações de valor histórico para a comunidade nem somente à idade corrente, fazendo visíveis as informações para funcionários internos a uma instituição. Seu caráter multifacetado não a estabelece como função que começa a desenvolver-se após a implementação de um arquivo permanente, mas que já começa a criar forma quando um usuário entende que precisa de uma informação, ou ainda antes, quando ele nem sabe que possui uma necessidade informacional. 
Nesse sentido, a difusão opera para aproximar usuários potenciais e manter os frequentes, num sentido de demonstrar à sociedade as possibilidades informacionais e formativas em um arquivo e compartilhar com essa população, as histórias indiciadas, as construções sociais expressadas em informações orgânicas (nos diferentes suportes) e hoje preservadas num arquivo.

Ortega (2013) defende que os usuários da informação são indivíduos que participam de um processo comunicacional, que se inicia com o reconhecimento da presença de uma ou mais necessidades informacionais, as quais podem ser identificadas pelo próprio usuário, ou pelo arquivista. Atrelado a isso, virá o processo de seleção das fontes que suprirão as necessidades determinadas e sua divulgação, respeitando critérios predeterminados. Como profissional da informação, o arquivista deve orientar o usuário na pesquisa e uso da informação, levando em conta suas características e as características da documentação pesquisada, porque assim, o usuário poderá desenvolver autonomia dentro deste espaço, que é social.

Em relação ao papel do arquivista nesse processo, Rockembach (2015, p. 105, grifo nosso) afirma que
[...] a difusão em arquivos consiste na busca de estratégias que visem a acessibilidade (facilitar o acesso, procurar vencer as barreiras tecnológicas e linguísticas), transparência (tornar público), atingir determinado público (através do marketing e demais ferramentas auxiliares), entender qual é o público (estudo de usuários e comportamento informacional), estudar as competências informacionais do público (literacia informacional / educação informacional, distinguindo-a da educação patrimonial), realizar a mediação (selecionar, filtrar, acrescentar qualidade informacional na recuperação de conteúdos), procurando uma maior proximidade dos usuários à informação contida nos acervos [...].

As ações do arquivista frente os processos de difusão da informação, exigem que ele esteja preparado para trabalhar com diferentes tipos de público, reconhecendo-os e adotando estratégias que contemplem as especificidades dos indivíduos que, como sociedade da informação, fazem parte do arquivo. Portanto, as habilidades desenvolvidas pelo arquivista são múltiplas e incluem uma instância de mediação, que será desenvolvida dentro da instituição, com "técnicas de organização e tratamento documental" (mediação implícita), para 
"tornar públicas e acessíveis as informações disponíveis que compõem os acervos documentais" (mediação explícita) (LOUSADA, 2015, p. 95-96).

Estes tipos de mediação cumprem a função de dar lugar aos diferentes tipos de usuários da informação, fazendo-os partícipes dos processos que ocorrem nos arquivos (públicos) e, portanto, fazendo-os partícipes da sua história. Isso faz com que a Arquivologia e os arquivos não existam para grandes mentes, grandes historiadores e literatos acadêmicos; e sim como construto social, retornem a toda sociedade para poder dotá-la de autoconhecimento e maior poder de atuação socioeconômico, político e cultural.

Assim, considerando seus aspectos sociais, integradores, orientadores, disseminadores, a difusão arquivística também pode ser chamada, parafraseando Sousa (2009), de uma "função matricial", porque reúne elementos que necessitam e se reportam às outras seis funções arquivísticas, numa relação de constante retroalimentação e por, como já abordamos, representar diretamente o objetivo maior de todas as demais funções, o acesso à informação (Figura 1):

\section{Figura 1 - A difusão como função matricial}

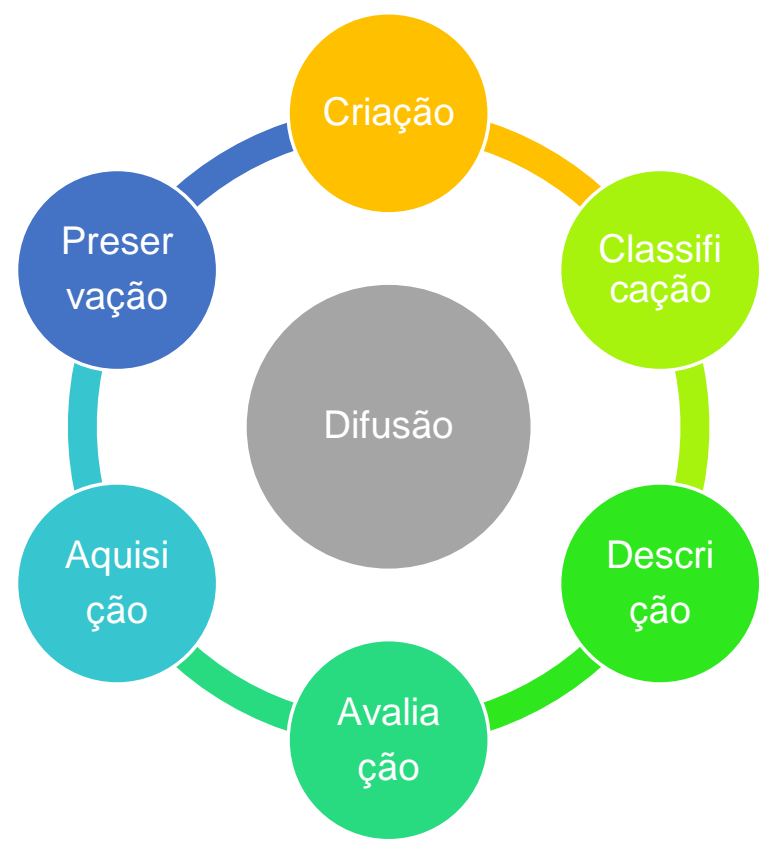

Fonte: Martendal (2018).

O processo comunicacional evidenciado por Ortega (2013) pode confirmar a situação da difusão como fundamental dentre as demais seis 
funções, na mesma proporção em que o usuário da informação pode ser posto como centro de um sistema documental e de informação (SANTAELLA RUIZ, 2005).

O usuário, como sujeito que usa a informação, está relacionado com todos os processos realizados na gestão documental, pois, como indivíduo e pertencente a uma comunidade, tem papel importante no eixo de discussão dos arquivos: ao se estabelecer um plano de classificação, na intenção de se organizar logicamente a informação, ao se elaborar palavras-chave e instrumentos de pesquisa, ao se estabelecer rotinas de preservação, evitando a deterioração do suporte e da informação, ao se estabelecer prazos de guarda, critérios de acessibilidade, entre outros. Relacionadas ao usuário da informação, estas ações não somente se direcionam a eles, mas também ocorre o inverso, a retroalimentação deste sistema, que observa o comportamento deste indivíduo/comunidade e implementa melhorias na unidade de informação (ARAÚJO, 2014).

Pelo fato de que podemos encontrar a difusão em múltiplos espaços do universo arquivístico, também podemos identificá-la como um processo que contempla diferentes estratégias para poder mostrar o que é um arquivo, para quê serve, quem é o arquivista e que trabalho realiza. Estas ações são identificadas dentro de um marco de processo formativo, do arquivista para os usuários. É por isso que se buscou considerar a difusão como ação educativa (PARRELA; KOYAMA, 2016), que pode ser realizada dentro e fora dos arquivos, em ambientes formais e não formais de educação.

\subsection{A Difusão Arquivística Como Processo Presente Em Instituições FormaIS E NÃo FormaIS dE EdUCAÇão}

Segundo Bellotto (2006), há três diferentes formas de proporcionar a difusão de documentos de caráter arquivístico, aqui denominada informação orgânica, quais sejam a difusão editorial, que se ocupa da elaboração de publicações, a difusão cultural, que "lança elementos de dentro do arquivo para fora [...] e a que permite o retorno dessa mesma política" (p. 228) e a assistência educativa, que busca promover serviços mediados entre arquivo e escola. 
Para a autora, essas três instâncias da difusão podem ocorrer concomitantemente e são mais frequentes em arquivos públicos, não excetuando sua prática em arquivos privados. Entendemos aqui, que existem múltiplas possibilidades de junção das três instâncias e infinitas outras, pois, ao compreender que um arquivo público contempla informações surgidas a partir de um cotidiano social, não é possível pensá-lo somente para pesquisadores que diariamente frequentam estes espaços; é preciso orientar seus serviços a atingir o maior número de pessoas possível, visto que, como sujeitos que vivem em sociedade, também compartilham das histórias e memórias evidenciadas nos arquivos.

Perpassando sobre o tema da memória, recorre-se a Halbwachs (1990), ao considerar que às histórias custodiadas por um arquivo, serão sobrepostas as memórias e opiniões de quem as vivenciou, ou seja, cidadãos que estão involucrados à realidade social em que vivem. São múltiplas as realidades de cada um desses cidadãos e amplas suas diferenças sociais, de formação, de visão de mundo.

E frente a estes aspectos e numa tentativa de categorizar os sujeitos, e, ou os tipos de usuários da informação em arquivos, Charbonneau (2008) os classifica como público relacionado à administração e público relacionado à pesquisa. Não obstante, a sociedade contemporânea é inclassificável nesse sentido, porque é múltipla e tem diferentes necessidades de informação. Só por isso, já é preciso identificar outro aspecto que norteará os serviços de arquivo: pensar em usuários potenciais e frequentes.

Um arquivo também é espaço de contemplação e de busca de informações desinteressadamente, como o explora Benjamin (2007), mas, sobretudo, é um espaço de re(construção) de cidadania, onde pessoas com diferentes capitais culturais ${ }^{1}$ encontrar-se-ão com diferentes necessidades informacionais e o arquivista deve estar preparado para lidar com elas, mirando sempre seguir o código de ética profissional, no que tange, entre outras questões, a "[...] facilitar o acesso aos arquivos ao maior número possível de

\footnotetext{
${ }^{1}$ BOURDIEU, P. Capital cultural, escuela y espacio social. Buenos Aires: Siglo Veintiuno Editores, 2014. $182 \mathrm{p}$.
} 
usuários, oferecendo seus serviços a todos com imparcialidade" (CIA, 1996, p. 2).

Por isso, as três instâncias de aplicação da difusão da informação, como as menciona Bellotto (2006), não se restringem ao arquivo e às instituições escolares, por exemplo, mas a todos os espaços em que a sociedade esteja presente, não se limitando à ida dessas pessoas ao arquivo, mas também, levando $o$ arquivo a elas.

Algumas iniciativas de aproximação do público aos arquivos podem ser observadas nas atividades desenvolvidas pelo Arquivo Público da Cidade de Belo Horizonte, por exemplo, que elaborou um "kit pedagógico de conservação", para que os visitantes do arquivo pudessem conhecer as práticas que os profissionais arquivistas levam a cabo diariamente. No intuito de aproximar o público potencial dos arquivos, também é possível lançar mão de contação de histórias nas escolas, utilizando como base documentos de arquivo, ou, por exemplo, de trabalhos de releitura de documentos, como o relatado pela Secretaria de Estado de Educação de Santa Catarina, em 2013: "A Escola de Educação Básica (EEB) Pero Vaz de Caminha, em Florianópolis, [realizou] [...] uma exposição com [...] releituras da carta de Pero Vaz de Caminha [...]" (SECRETARIA DE ESTADO DA EDUCAÇÃO, 2013).

O arquivista, como profissional da informação, pode também ser formador/educador. Entendido sob o olhar de Souto (2017), "[...] formar não é ensinar, não é transmitir conhecimentos, ainda que isto tenha lugar no processo. É, em sua relação com a reflexão, desenvolver capacidades reflexivas que acompanham o que fazer cotidiano na prática docente" (p. 71, tradução nossa). Transferindo o mesmo conceito à Arquivologia, pensa-se na atuação do arquivista no sentido de construir caminhos de mediação entre os usuários frequentes e potenciais da informação orgânica, localizada nos arquivos, adequando estratégias para cada tipo de usuário, a fim de poder oferecer serviços de informação que contemplem as necessidades informacionais presentes. Também deve ser um motivador da divulgação no/do arquivo como espaço (in)formativo, de cultura e lazer, destituindo a visão de que arquivos são espaços desconhecidos, ou somente de guarda de papéis. 
O caráter educativo da difusão, em relação à documentação que é divulgada e ao público que é envolvido, identifica o arquivo como espaço formativo. Langhi e Nardi (2009), nesse sentido, mencionam que o museu oferece educação não formal, mas, de acordo com a "assistência educativa", defendida por Bellotto (2006), pode-se afirmar que o arquivo segue esta mesma linha:

[...] alguns exemplos de locais que oferecem a educação não formal são: museus, meios de comunicação, agências formativas para grupos sociais específicos, organizações profissionais, instituições não convencionais de educação que organizam eventos tais como cursos livres, feiras e encontros [...] (LANGHI; NARDI, 2009, p. 03).

No sentido de conjugar os saberes dos arquivistas com os serviços de difusão de informações para o público, nota-se o caráter de profissional de referência do arquivista, que se encontra presente em todas as suas atividades, interna ou externamente ao ambiente do arquivo, trabalhando desde a produção da informação orgânica à organização e acesso as mesmas. A todo momento, 0 arquivista se coloca como agente e suas ações refletem no funcionamento do arquivo e no reconhecimento deste arquivo pelo público, remodelando e reconcebendo, constantemente, este espaço de construções sociais, que, como afirma Araújo (2018, p. 61), considera o uso da informação como processo que envolve "imaginação, apropriação, questionamentos [e] tensionamentos".

\section{ASPECTOS METODOLÓGICOS}

Para a consecução deste trabalho de pesquisa, foi adotado o enfoque qualitativo como lógica de pesquisa e a estratégia metodológica de análise de conteúdo, para cumprir o objetivo de "caracterizar a abordagem da difusão arquivística nos currículos dos cursos de graduação em Arquivologia no Brasil".

Ao usar a técnica de análise de conteúdo evidenciada por Bardin (2011), considerou-se a estratégia metodológica mais assertiva para poder identificar as "mensagens" transmitidas por cada currículo, no que tangia às disciplinas que conformam cada um desses documentos. Para a autora, a técnica de análise de conteúdo compreende três etapas: a pré-análise, a exploração do material e o tratamento dos resultados e interpretações (BARDIN, 2011). 
Nesse sentido, considerando as unidades que compõem cada uma das três etapas mencionadas, alguns elementos auxiliaram no momento da consecução da análise, como se pode observar no Quadro 1:

Quadro 1 - Etapas da análise de conteúdo aplicadas à pesquisa

\begin{tabular}{|c|l|}
\hline $\begin{array}{c}\text { Características } \\
\text { da análise de } \\
\text { conteúdo }\end{array}$ & \multicolumn{1}{|c|}{ Desenvolvimento da pesquisa } \\
\hline $\begin{array}{c}\text { Unidades de } \\
\text { registro }\end{array}$ & $\begin{array}{l}\text { Títulos e ementas das disciplinas das 16 universidades } \\
\text { que possuem o curso de graduação em Arquivologia. }\end{array}$ \\
\hline $\begin{array}{c}\text { Unidades de } \\
\text { contexto }\end{array}$ & $\begin{array}{l}\text { Diretrizes curriculares para os cursos de graduação em } \\
\text { Arquivologia do Brasil, dispostos pelo Ministério da } \\
\text { Educação (suas resoluções e pareceres). }\end{array}$ \\
\hline & $\begin{array}{l}\text { 1. Difusão, divulgação, disseminação, marketing; } \\
\text { 2. Acesso, utilização, consulta; } \\
\text { 3. Educa*2, pedago*; } \\
\text { 4. Cultura*; } \\
\text { 5. Descri*, representação; } \\
\text { 6. Mediação, competência, comunicação; } \\
\text { 7. Arquivo permanente / Arquivos permanentes; } \\
\text { 8. Estudo de usuário / Estudo de usuários / Estudos de } \\
\text { usuários, público. }\end{array}$ \\
\hline
\end{tabular}

Fonte: Dados da pesquisa (2018), baseados em Bardin (2011).

Cada uma das categorias, mencionadas no quadro acima, foram escolhidas a partir das aproximações/sinônimos do termo "difusão" encontrados na literatura pesquisada. Dentro do escopo dos currículos, cada disciplina foi esmiuçada, levando à observação de seu título, objetivos e bibliografia, em diferentes etapas.

A primeira etapa da análise de conteúdo consistiu em identificar a presença de cada uma das categorias no título e ementa de cada uma das disciplinas das 16 universidades pesquisadas. Logo, como segunda etapa, se procedeu a um segundo filtro, que buscava confirmar se a disciplina estava direcionada à difusão na Arquivologia. Por isso, buscou-se identificar: a) se o objetivo da disciplina é o ensino da difusão na Arquivologia; e em segunda instância, b) se o título e, ou a ementa da disciplina contemplam os termos "arquivo" e seus derivados, "unidade(s) de informação", "acervo", "informação".

\footnotetext{
$2 \mathrm{O}$ asterisco $\left(^{*}\right)$ presente em alguns dos termos indica que a busca categorial no texto das
} disciplinas engloba termos derivados dos prefixos citados. 
Em uma terceira etapa, já correlacionando as interpretações realizadas sobre os textos dos currículos, foram observadas a bibliografia básica e, ou complementar proposta para o oferecimento de cada uma das disciplinas relacionadas à difusão.

\section{RESULTADOS}

Os resultados apresentados a seguir possibilitam compreender como se delineia e desenvolve, a temática da difusão no ensino em cursos de graduação em Arquivologia no Brasil.

Na pré-análise, a exploração do material e o tratamento dos resultados e interpretações foram etapas da análise de conteúdo que permitiram inferir diferentes aspectos sobre a abordagem da difusão nos currículos dos cursos de graduação em Arquivologia no Brasil.

A partir da pré-análise, foi possível identificar que tipos de documentos fariam parte da pesquisa, cuja delimitação obedeceu que o corpo da análise de conteúdo fosse composto por currículos das 16 universidades públicas, de esfera estadual, ou federal, que ministram o curso de graduação em Arquivologia no Brasil. Os aspectos transversais, também considerados para a análise, levaram em conta, além do nome da universidade e sua localização geográfica, o ano de criação do curso e a data de atualização curricular mais recente, em relação ao período da coleta de dados, de meados de 2017 a janeiro de 2018.

Das 16 universidades, se desprende uma lista, cuja distribuição geográfica se localiza nas regiões Norte (UFAM, UFPA), Nordeste (UFPB, UFBA, UEPB), Centro-Oeste (UNB), Sudeste (UFF, UFES, UFMG, UNIRIO, UNESP) e Sul (UFSC, UFSM, FURG, UEL, UFRGS). Os dados referidos a cada uma das 16 universidades, quanto às atualizações curriculares, variam entre os anos de 2003 a 2017 e distribui cada uma das instituições conforme o Quadro 2 a seguir: 
Quadro 2 - Cursos de graduação em Arquivologia no Brasil pesquisados

\begin{tabular}{|c|c|}
\hline Universidade & $\begin{array}{c}\text { Atualização curricular } \\
\text { mais recente }\end{array}$ \\
\hline Universidade Estadual de Londrina (UEL) & 2018 \\
\hline Universidade Federal do Espírito Santo (UFES) & 2017 \\
\hline Universidade Federal do Rio Grande (FURG) & $2017^{3}$ \\
\hline Universidade Estadual da Paraíba (UEPB) & 2016 \\
\hline Universidade Federal de Santa Catarina (UFSC) & 2016 \\
\hline Universidade Federal de Minas Gerais (UFMG) & 2015 \\
\hline Universidade Federal do Rio Grande do Sul \\
(UFRGS) & 2014 \\
\hline Universidade Federal do Pará (UFPA) & 2014 \\
\hline Universidade Federal do Estado do Rio de Janeiro & 2013 \\
\hline (UNIRIO) & 2012 \\
\hline Universidade Estadual Paulista “Júlio de Mesquita & 2010 \\
\hline Filho" (UNESP) & 2009 \\
\hline Universidade Federal da Bahia (UFBA) & 2008 \\
\hline Universidade Federal do Amazonas (UFAM) & 2006 \\
\hline Universidade Federal da Paraíba (UFPB) & 2004 \\
\hline Universidade de Brasília (UNB) & 2003 \\
\hline Universidade Federal de Santa Maria (UFSM) & \\
\hline Universidade Federal Fluminense (UFF) & \\
\hline
\end{tabular}

Fonte: Dados da pesquisa (2018), baseados em Universidade Federal do Estado do Rio de Janeiro (2018), Universidade Federal de Santa Maria (2018), Universidade Federal Fluminense (2018), Universidade de Brasília (2018), Universidade Federal da Bahia (2018), Universidade Estadual de Londrina (2018), Universidade Federal do Espírito Santo (2018), Universidade Federal do Rio Grande do Sul (2018), Universidade Estadual Paulista (2018), Universidade Estadual da Paraíba (2018), Universidade Federal do Amazonas (2018), Universidade Federal do Rio Grande (2018), Universidade Federal da Paraíba (2018), Universidade Federal de Minas Gerais (2018), Universidade Federal de Santa Catarina (2018) e Universidade Federal do Pará (2018).

De acordo com os oito grupos categoriais interpostos à pesquisa (relembrados na Tabela 1), buscou-se, a partir de dos títulos e ementas das 997 disciplinas compreendidas pelos 16 currículos pesquisados, identificar aquelas disciplinas que apresentam em seu escopo à temática da difusão arquivística, e obteve-se o resultado de 67 disciplinas que, segundo os dados apresentados por seus títulos e ementas, são em sua maioria obrigatórias nos currículos e se relacionam à difusão arquivística, distribuídas conforme a Tabela 1:

\footnotetext{
${ }^{3}$ Segundo o website da FURG, não há menção à data da última atualização curricular realizada, porém o denominado "Quadro de Sequência Lógica" das disciplinas do curso foi atualizado pela última vez em 2017.
} 
Tabela 1 - Total de disciplinas recuperadas por categoria

\begin{tabular}{cc}
\hline Categoria & Disciplinas recuperadas \\
\hline Categoria 1: Difusão, divulgação, & 16 \\
disseminação, marketing. & 02 \\
Categoria 2: Acesso, utilização, consulta; & 03 \\
Categoria 3: Educa*, pedago*. & 03 \\
Categoria 4: Cultura*. & 19 \\
Categoria 5: Descri*, representação; & 02 \\
Categoria 6: Mediação, competência, \\
comunicação. \\
Categoria 7: Arquivo permanente / \\
Arquivos permanentes. \\
Categoria 8: Estudo de usuário / Estudo \\
de usuários / Estudos de usuários, \\
público.
\end{tabular}

Fonte: Dados da pesquisa (2018).

Dentre as 67 disciplinas encontradas a partir das buscas realizadas, encontram-se os mais variados títulos de disciplinas que se orientam direta, ou transversalmente ao ensino da difusão na perspectiva da Arquivologia. São exemplos: "Difusão arquivística" (FURG), "Marketing em serviços de informação" (UFBA), "Referência e difusão em arquivos" (UFSM), "Gestão de arquivos" (UFAM), "Ação cultural em unidades de informação" (UFF), "Difusão em arquivos" (UEL), "Mediação cultural em arquivos" (UFES), "Arquivos permanentes" (UFF), "Usos e usuários da informação arquivística" (UEPB) (MARTENDAL, 2020).

Tais disciplinas se distribuem em seus currículos em proporções diferentes, em relação ao total de disciplinas que compõem cada curso de graduação em Arquivologia. No entanto, ao realizar uma terceira etapa da análise, levando em conta a bibliografia proposta para cada uma das 67 disciplinas, considerando bibliografia básica e complementar, entendeu-se que três disciplinas não se relacionavam diretamente à temática da difusão, ainda que seu título e ementa assim o fizessem parecer.

Constando de 64 disciplinas representativas direta, ou transversalmente, da temática da difusão na Arquivologia, a quantidade de disciplinas por categoria de análise está distribuída conforme o Gráfico 1 a seguir: 


\section{Gráfico 1 - Categorias da análise de conteúdo versus quantidade de disciplinas encontradas}

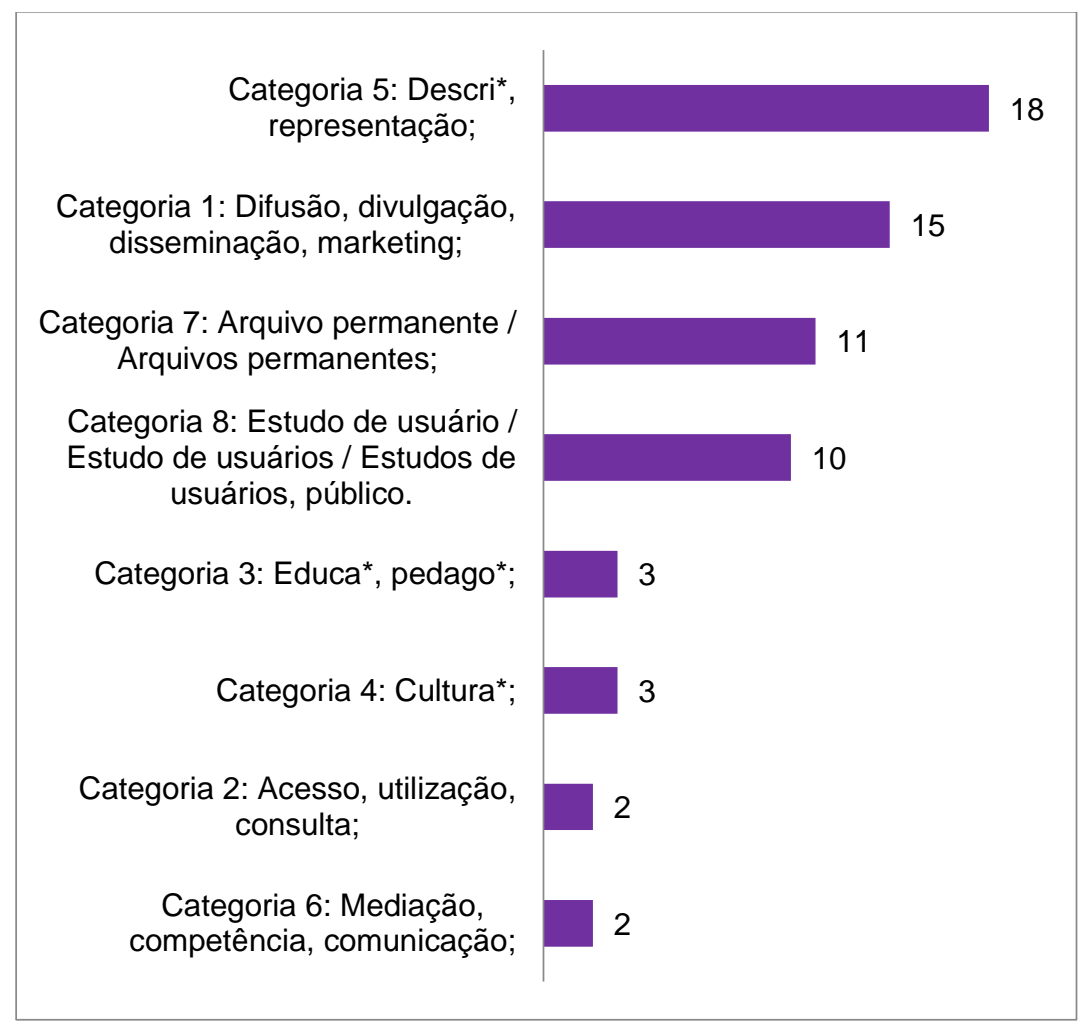

Fonte: Dados da pesquisa (2018).

Liderando os resultados da análise de conteúdo, com 18 disciplinas está a Categoria 5, seguida da Categoria 1, específica sobre a difusão na Arquivologia, com 15 disciplinas. A Categoria 8 está presente em 10 disciplinas e aborda especificamente sobre a identificação dos usuários da informação orgânica, suas metodologias e serviços de informações que respondam a essas demandas, enquanto que a Categoria 6 , que engloba as habilidades do profissional arquivista no tocante às atividades de referência com os usuários dos arquivos, conta com somente duas disciplinas vinculadas.

Levando em conta as atualizações curriculares de cada uma das universidades, a UFPB possui mais disciplinas relacionadas à difusão no âmbito da Arquivologia e sua atualização curricular mais recente ocorreu em 2008. A UFRGS, de atualização curricular mais recente em 2014, é a universidade que possui menos disciplinas relacionadas à temática pesquisada e a UEL, que atualizou seu currículo em 2018, possui quatro disciplinas, entrando no grupo com UNIRIO, UFMG e UFES (Gráfico 2). Estes resultados são peculiares, tendo 
em vista principalmente a emergência da Lei no 12.527 no ano de 2011, momento em que se coloca mais em evidência a questão do acesso à informação pública, definindo também novos olhares para o ensino da Arquivologia e para o acesso orientado à informação.

\section{Gráfico 2- Atualização curricular versus quantidade de disciplinas}

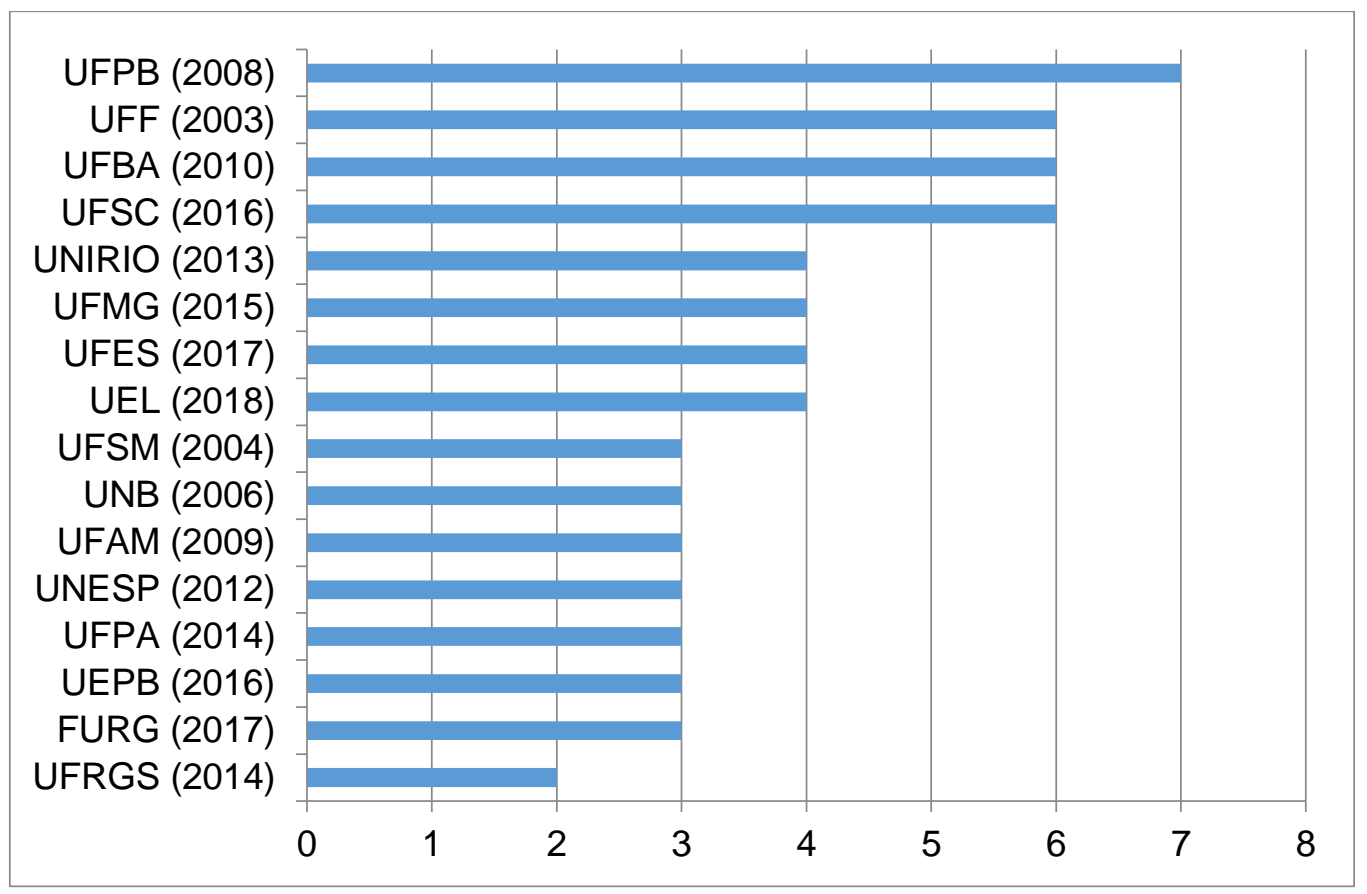

Fonte: Dados da pesquisa (2018).

Os dados obtidos como resultados desta pesquisa conformam apenas uma parcela de toda a área de pesquisa compreendida pela difusão dentro do escopo da Arquivologia. Levando em conta sua característica matricial em relação às outras seis funções da Arquivologia e devido à sua aproximação com - objetivo básico dos arquivos de guardar e dar acesso à informação (ROUSSEAU; COUTURE, 1998), a difusão se coloca como temática que busca estar presente nas diferentes esferas que a Arquivologia pode abarcar.

Cabe refletir, como recomendação para próximos estudos sobre a temática, sobre a incorporação da difusão como eixo central em congressos como o Congresso Nacional de Arquivologia, que em sua edição de 2018 trabalhou "Ética responsabilidade social e políticas de acessibilidade para a arquivologia". Os trabalhos apresentados em congressos e demais eventos na área de Arquivologia são também importantes contribuições para o avanço das 
pesquisas sobre difusão.

Considera-se que a relação que a Arquivologia estabelece com a disponibilização e o acesso à informação se reflete também na convergência de publicações sobre a temática, desenvolvendo-se cada vez mais amplamente e na incorporação de conteúdos às disciplinas ministradas em cursos de graduação, além da utilização de bibliografia específica e atualizada, considerando que cada vez mais a difusão é discutida como central para a Arquivologia atual.

\section{CONSIDERAÇÕES FINAIS}

As considerações finais deste estudo buscam impulsionar mais pesquisas sobre a difusão arquivística e sobre o caráter ativo dos usuários e do arquivista frente à gestão da informação e às ações educativas realizadas por/em/com arquivos.

Das primeiras conclusões, evidencia-se que a pesquisa nos 16 currículos dos cursos e nos programas das disciplinas se configura como relevante para que os estudos sobre o ensino da Arquivologia produzam aplicações práticas em sala de aula, tais como a atualização da bibliografia, a incorporação de concepções em torno do paradigma social da Ciência da Informação, considerando a emergência de um usuário ativo, que requer do arquivista ações eficientes e acordes ao avanço tecnológico.

Observa-se que a categoria " 5 Descri*, representação." apresenta a maior concentração de disciplinas: 18, seguida pelas categorias "1 Difusão, divulgação, disseminação, marketing.", com 15, "7 Arquivo permanente / Arquivos permanentes.", com 11, e "8 Estudo de usuário / Estudos de usuário / Estudos de usuários, público.", com 10. Nota-se, com isso, que na maior parte dos currículos há indicativos de atenção em ministrar disciplinas sobre a descrição de documentos de arquivo que, além de ser uma das sete funções basilares da Arquivologia, dá vazão à produção de instrumentos de pesquisa, que servirão para a divulgação de acervos. Em concordância, Barros (2014), quando apresenta o termo "representação arquivística", pensa na descrição e classificação como as funções arquivísticas que mais se relacionam com a 
difusão, pelo fato de instrumentos como guias, catálogos, ou o plano de classificação servirem de base para a pesquisa no arquivo.

A categoria "1 Difusão, divulgação, disseminação, marketing;", por sua vez, que está relacionada com a elaboração de serviços e produtos para a difusão na Arquivologia em arquivos e outras instituições concentra disciplinas sobre serviços educativos, difusão cultural, marketing em arquivos, que fomentam projetos e a criação de produtos para aproximar os públicos potencial e frequente. É interessante observar que os currículos estão numa crescente aproximação com a temática.

A grande concentração de disciplinas na categoria "7 Arquivo permanente / Arquivos permanentes;" demonstra que, além de ser uma das idades do ciclo de vida documental, a idade permanente concentra ainda a terceira posição (com 11 disciplinas encontradas), dentre as categorias aqui apresentadas, com propostas de ações de difusão e nos permite inferir que há ausência de disciplinas que abordem a temática aplicada às idades corrente e intermediária.

Fazendo menção à tríade arquivista-informação orgânica-público, a proximidade de grande parte das disciplinas com os estudos de usuários é fundamental para se pensar a difusão na Arquivologia, afinal a difusão envolve o "para quem" o acervo e os serviços do arquivo estão direcionados e, quando contemplada grande parte das disciplinas nesta categoria, entende-se que a difusão está sendo levada em conta nestes currículos.

Deduz-se, contudo, a contraponto, que há poucas disciplinas que abordem o caráter social do profissional arquivista, em atividades de mediação e referência, por exemplo. Por isso, mesmo que seja possível vislumbrar aproximações das disciplinas com a difusão na Arquivologia, o processo formativo do arquivista ainda encontra-se desvinculando as práticas de difusão às habilidades que o arquivista deve desenvolver para isso, o que consiste em saber reconhecer os públicos do arquivo e propor produtos e programas para difusão do acervo. Dentro das disciplinas relacionadas à categoria "8 Estudo de usuário / Estudo de usuários / Estudos de usuários, público", por exemplo, há o enfoque no público, em seu comportamento e preferências de pesquisa, porém a diferença está em que o arquivista não saberá lidar com este público, caso 
desconheça que ele - o arquivista - também exerce o papel de educador dentro do arquivo e de que maneira deve exercer estas funções.

Observa-se também, positivamente, que das disciplinas relacionadas à difusão, sua maioria (53) estabelece a função de obrigatória dentro dos currículos, enquanto que somente 11 delas são optativas, o que nos possibilita inferir que, ainda que incipiente o ensino da difusão nos cursos de graduação, o fato de que sejam obrigatórias confere mais garantia de que a disciplina seja ministrada durante o curso.

As informações contidas no Gráfico 2 permitem inferir que não necessariamente os cursos que possuem as maiores concentrações de disciplinas relacionadas à difusão são aqueles de atualização curricular mais recente, exemplo para o qual podemos considerar a UFPB, a UFF, a UFBA e a UFSC, cuja atualização curricular segue os anos, respectivamente 2008, 2003, 2010 e 2016, propondo a interpretação de que, mesmo há quase 15 anos atrás (caso da UFF), já se dava ênfase ao ensino de disciplinas afeitas à difusão na Arquivologia. A aparição destas disciplinas foi acontecendo em diferentes proporções em cada universidade, não havendo grandes saltos qualitativos à medida que a data se aproximava de 2018.

Pode-se dizer que a emergência da corrente Integrada da Arquivologia, como momento de evolução de um pensamento voltado à democratização do acesso e utilização da informação orgânica e pública é um dos motivos para que haja cada vez mais disciplinas relacionadas à difusão na Arquivologia e que este fato é contributivo para as reconstruções periódicas dos currículos.

Para a análise destes instrumentos comunicacionais, as ementas de cada disciplina foram subsídios que suscitaram informações como os objetivos ao ensinar a difusão, os tipos de público contemplados por este processo, bem como quais ações, projetos, ou políticas podem ser construídos, para que o arquivista esteja apto a dar acesso orientado às informações que estarão sob sua custódia. Neste sentido, os currículos dos cursos foram subsídios fundamentais para a consecução desta pesquisa e se pretende que continuem sendo motores propulsores para pesquisa em Arquivologia em todo o país. 


\section{AGRADECIMENTO}

O presente trabalho foi realizado com apoio da Coordenação de Aperfeiçoamento de Pessoal de Nível Superior - Brasil (CAPES) - Código de Financiamento 001.

\section{REFERÊNCIAS}

ALBERCH I FUGUERAS, Ramón. Los archivos, entre la memoria histórica y la sociedad del conocimiento. Barcelona: Editorial UOC, 2003. $221 \mathrm{p}$.

ARAÚJO, Carlos Alberto Ávila. Arquivologia, Biblioteconomia, Museologia e Ciência da Informação: o diálogo possível. Brasília: Briquet de Lemos, 2014. 200 p.

ARAÚJO, Carlos Alberto Ávila. O que é ciência da informação. Belo Horizonte: KMA, 2018. 132p.

BARDIN, Laurence. Análise de conteúdo. Lisboa: Edições 70, 2011. 280 p.

BARROS, Thiago Henrique Bragato. A representação da informação Arquivística: Uma Análise do discurso teórico e institucional a partir dos contextos Espanhol, Canadense e Brasileiro. 2014. 222f. Tese (Doutorado em Ciência da Informação) - Universidade Estadual Paulista, Faculdade de Filosofia e Ciências, Marília, 2014. Disponível em: https://repositorio.unesp.br/bitstream/handle/11449/110391/000792879.pdf?seq uence=1\&isAllowed=y. Acesso em: 15 out. 2019.

BELLOTTO, Heloísa Liberalli. Difusão editorial, cultural e educativa em arquivos. In: BELLOTTO, Heloísa Liberalli. Arquivos permanentes: tratamento documental. 4. Ed. Rio de Janeiro: FGV, 2006. Cap. 14. p. 227-247.

BENJAMIN, Walter. Paris, capital do século XIX. In: BENJAMIN, Walter. Passagens. Belo Horizonte/São Paulo: Editora UFMG/Imesp, 2007. p. 30-43.

CAPURRO, Rafael. Epistemología y Ciencia de la Información. 2003. Disponível em: http://www.capurro.de/enancib.htm. Acesso em: 06 out. 2019.

CASTELLS, Manuel. Prólogo: a rede e o ser. In: CASTELLS, Manuel. A sociedade em rede. 17. ed. São Paulo: Paz e Terra, 2016. v.1. p. 61-85.

CHARBONNEAU, Normand. La diffusion. In: COUTURE, Carol et al. Les Fonctions de l'Archivistique Contemporaine. Québec: Presses de L'université du Québec, 2008. Cap. 8. p. 373-428. 
CIA. Código de Ética. 1996. Disponível em:

https://www.ica.org/sites/default/files/ICA_1996-09-

06_code\%20of\%20ethics_PT.pdf. Acesso em: 06 out. 2019.

HALBWACHS, M. A memória coletiva. São Paulo: Centauro, 1990.189 p.

LANGHI, Rodolfo; NARDI, Roberto. Ensino da astronomia no Brasil: educação formal, informal, não formal e divulgação científica. Revista Brasileira de Ensino de Física, São Paulo, v. 31, n. 4, p. 4402-4412, dez. 2009. Disponível em:

http://www.scielo.br/scielo.php?script=sci_arttext\&pid=S1806-

$11172009000400014 \&$ Ing=en\&nrm=iso. Acesso em: 06 out. 2019.

LOUSADA, Mariana. A mediação da informação na Teoria Arquivística. 2015. 135 f. Tese (Doutorado em Ciência da Informação) - Universidade Estadual Paulista, Faculdade de Filosofia e Ciências, Marília, 2015.

MARTENDAL, F. F. Difusão na Arquivologia e suas expressões nos cursos de graduação em Arquivologia no Brasil. 2018. 279 f. Dissertação (Mestrado em Ciência da Informação) - Universidade Federal de Santa Catarina, Florianópolis, 2018. Disponível em:

https://repositorio.ufsc.br/bitstream/handle/123456789/186800/PCIN0171-

D.pdf?sequence=-1\&isAllowed=y. Acesso em: 06 out. 2019.

ORTEGA, Cristina Dotta. Ciência da Informação: do objetivo ao objeto. In: RENDÓN ROJAS, Miguel Ángel. El objeto de estudio de la bibliotecología / documentación / ciencia de la información: propuesta, discusión, análisis y elementos comunes. Cidade do México: Instituto de Investigaciones Bibliotecológicas y de la Información, 2013, p. 151-177.Disponível em: http://132.248.242.6/ publica/conmutarl.php?arch=1\&idx=275. Acesso em: 06 out. 2019.

PARRELA, Ivana Denise; KOYAMA, Adriana Carvalho (Org.). Simpósio temático Arquivos \& Educação. Belo Horizonte: Escola de Ciência da Informação, Programa de Pós-graduação em Ciência da Informação, 2016. 144 p. Disponível em: https://drive.google.com/file/d/0BBESfxHN3OgVzIEOUk5Q29KNjg/view. Acesso em: 17 out. 2019.

ROCKEMBACH, Moisés. Difusão em arquivos: uma função arquivística, informacional e comunicacional. Informação Arquivística, Rio de Janeiro, v. 4, n. 1, p. 98-118, out. 2015. Disponível em:

http://www.aaerj.org.br/ojs/index.php/informacaoarquivistica/article/view/95. Acesso em: 06 out. 2019.

ROUSSEAU, Jean-Yves; COUTURE, Carol. Os fundamentos da disciplina arquivística. Lisboa, Portugal: Publicações Dom Quixote, 1998. 356p.

SANTAELLA RUIZ, Rita Dolores. Perspectiva sistémica de los estudios de usuarios de información. Forinf@, Madrid, v.29, p.7-15, 2005. 
SECRETARIA DE ESTADO DA EDUCAÇÃO. Escola Pero Vaz de Caminha completa 52 anos. 2013. Disponível em:

http://www.sed.sc.gov.br/imprensa/noticias/24452-escola-pero-vaz-de-caminhacomemora-52-anos. Acesso em: 06 out. 2019.

SOUSA, Renato Tarciso Barbosa de. A classificação como função matricial do que- fazer arquivístico. In: SANTOS, Vanderlei Batista dos; INNARELLI, Humberto Celeste; SOUSA, Renato Tarciso Barbosa de. (Org.). Arquivística: temas contemporâneos: classificação, preservação digital, gestão do conhecimento. Distrito Federal: SENAC, 2009. p. 77-172.

SOUTO, M. Pliegues de la formación: sentidos y herramientas para la formación docente. Rosario: Homo Sapiens Ediciones, 2016. 256p.

UNIVERSIDADE DE BRASÍLIA. Curso de Graduação em

Arquivologia. 2018. Disponível em: http://arquivologia.fci.unb.br/. Acesso em: 17 jan. 2018.

UNIVERSIDADE ESTADUAL DA PARAÍBA. Curso de Graduação em Arquivologia. 2018. Disponível em: http://arquivologiauepb.com.br/. Acesso em: 06 out. 2019.

UNIVERSIDADE ESTADUAL DE LONDRINA. Curso de Graduação em Arquivologia. 2018. Disponível em: http://www.uel.br/ceca/cin/. Acesso em: 06 out. 2019.

UNIVERSIDADE ESTADUAL PAULISTA “JÚLIO DE MESQUITA FILHO”. Curso de Graduação em Arquivologia. 2018. Disponível em: http://www.marilia.unesp.br/\#!/graduacao/cursos/arquivologia/. Acesso em: 06 out. 2019.

UNIVERSIDADE FEDERAL DA BAHIA. Curso de Graduação em

Arquivologia. 2018. Disponível em: https://blog.ufba.br/ici/ensino/arquivologia/. Acesso em: 06 out. 2019.

UNIVERSIDADE FEDERAL DA PARAÍBA. Curso de Graduação em Arquivologia. 2018. Disponível em: http://www.ccsa.ufpb.br/arqv. Acesso em: 06 out. 2019.

UNIVERSIDADE FEDERAL DE MINAS GERAIS. Curso de Graduação em Arquivologia. 2018. Disponível em: http://colgradarquivo.eci.ufmg.br/. Acesso em: 06 out. 2019.

UNIVERSIDADE FEDERAL DE SANTA CATARINA. Curso de Graduação em Arquivologia. 2018. Disponível em: http://arquivologia.ufsc.br/. Acesso em: 06 out. 2019.

UNIVERSIDADE FEDERAL DE SANTA MARIA. Curso de Graduação em Arquivologia. 2018. Disponível em: http://w3.ufsm.br/arquivologia/. Acesso em: 06 out. 2019. 
UNIVERSIDADE FEDERAL DO AMAZONAS. Curso de Graduação em Arquivologia. 2018. Disponível em: http://www.ufam.edu.br/unidadesacademicas/capital/instituto-de-filosofia-ciencias-humanas-e-sociais/18ufam/institucional/unidades-academicas. Acesso em: 06 out. 2019.

UNIVERSIDADE FEDERAL DO ESPÍRITO SANTO. Curso de Graduação em Arquivologia. 2018. Disponível em: http://www.arquivologia.ufes.br/. Acesso em: 06 out. 2019.

UNIVERSIDADE FEDERAL DO ESTADO DO RIO DE JANEIRO. Curso de Graduação em Arquivologia. 2018. Disponível em: http://www.unirio.br/arquivologia. Acesso em: 06 out. 2019.

UNIVERSIDADE FEDERAL DO PARÁ. Curso de Graduação em Arquivologia. 2018. Disponível em: http://www.icsa.ufpa.br/index.php/arquivologia. Acesso em: 06 out. 2019.

UNIVERSIDADE FEDERAL DO RIO GRANDE DO SUL. Curso de Graduação em Arquivologia. 2018. Disponível em: http://www.ufrgs.br/fabico/. Acesso em: 06 out. 2019.

UNIVERSIDADE FEDERAL DO RIO GRANDE. Curso de Graduação em Arquivologia. 2018. Disponível em: http://www.arquivologia.furg.br/. Acesso em: 06 out. 2019.

UNIVERSIDADE FEDERAL FLUMINENSE. Curso de Graduação em Arquivologia. 2018. Disponível em: http://www.uff.br/?q=curso/arquivologia/12684/bacharelado/niteroi. Acesso em: 06 out. 2019.

\title{
ARCHIVAL DIFFUSION AND ITS EXPRESSIONS IN THE ARCHIVAL SCIENCE UNDERGRADUATE COURSES IN BRAZIL
}

\begin{abstract}
Introduction: The diffusion is the function of Archival Science related to the divulgation of the records and information services intermediated by archivists, and it is identified by its inclusive character, because get together the information users (potential and frequent, suiting to the provided services) to informational capital. Objective: Recognizing the role of the archival diffusion in the teaching of Archival Science in Brazil, this article is focused to characterize the archival diffusion approach into the curricula of the Archival Science undergraduate courses in Brazil. Methodology: As methods, this research considered the qualitative research logic, using the content analysis as an instrument. Results: As results, with the analyzed curricula it was observed that the subjects that work about the diffusion are majority required and approached of different focus and they use, for their teaching-learning process, different bibliography. Conclusions: It concludes that in the Archival Science curricula the diffusion is approached, mostly in the subjects about archival description, followed by subjects
\end{abstract}


rightly related to information diffusion and, in a short proportion, to the subjects related to mediation, literacy and information communication.

Descriptors: Information dissemination. Organic information. Curricula. Teaching plan.

\section{DIFUSIÓN ARCHIVÍSTICA Y SUS EXPRESIONES EN LAS CARRERAS DE GRADO EN ARCHIVOLOGÍA EN BRASIL}

\section{RESUMEN}

Introducción: La difusión es la función de la Archivología que se relaciona con la divulgación de los acervos y servicios de información intermediada por archivistas y es identificada por su carácter inclusivo, al reunir los usuarios de la información (potenciales y frecuentes, adecuando los servicios brindados) con el capital informacional. Objetivo: Reconociendo el rol fundamental de la temática "difusión" en la enseñanza de grado en Archivología en Brasil, este artículo se ocupará de caracterizar el abordaje de la difusión archivística en los planes de estudio de las carreras de grado en Archivología en Brasil. Metodología: Como aspectos metodológicos, la presente investigación há considerado la lógica de investigación cualitativa, usando el análisis de contenido como instrumento. Resultados: Como resultados, respecto a los planes de estudio analizados, se ha observado que las asignaturas que trabajan la temática de la difusión, en su mayoría de cursada obligatoria, la abordan con diferentes enfoques y utilizan, para su enseñanza, diferentes bibliografías. Conclusiones: Se concluye que en los planes de estudio de Archivología la difusión es abordada, mayoritariamente, en las asignaturas vueltas a la descripción archivística, seguida por asignaturas vueltas directamente a la difusión de la información y, con menor proporción, a las asignaturas relacionadas a mediación, alfabetización informacional y comunicación de la información.

Descriptores: Diseminación de la información. Información orgánica. Planes de estudio. Programas de asignaturas.

Recebido em: 06.11.2019

Aceito em: 13.06.2020 